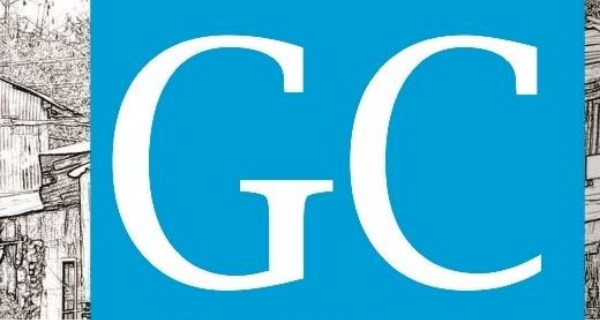

Revista Nacional de

Gerenciamento de Cidades

\title{
PROPOSTA PARA ESGOTAMENTO SANITÁRIO EM HABITAÇÕES DE INTERESSE SOCIAL NO TOCANTINS, BRASIL
}

\author{
Eleana Patta Flain ${ }^{1}$
}

Roberto Righi ${ }^{2}$

\begin{abstract}
RESUMO
O tema do trabalho é uma nova proposta alternativa para a questão do esgotamento sanitário em Habitações de Interesse Social no estado do Tocantins, que pode contribuir para a melhoria das condições urbanas. O objetivo é a preservação do meio ambiente e a melhoria da saúde pública. A justificativa decorre do grande crescimento demográfico e a desregrada expansão dos perímetros urbanos das cidades deste relativamente novo (25 anos) estado do Tocantins, associados a degradação da saúde pública, do meio ambiente e da paisagem urbana; que tornam indispensável a avaliação e urgente adequação daquela realidade. Esta providência se refere as cidades de menor porte. A metodologia empregada para a realização desta proposta técnica alternativa iniciou-se com análise de referências documentais e ulterior levantamento em campo. Como resultados este artigo apresenta inicialmente alguns conceitos referentes às teorias de sistemas de esgotamento sanitário e um breve estudo da atual condição dos sistemas de esgotamento sanitário para habitação de interesse social no Brasil. A partir destes fundamentos e com os dados obtidos em levantamento em campo, do estudo de casos, foi possível a realização da proposta final. Como conclusões a situação hoje precária e degradante é substituída pela implantação de um sistema integrado que abrange desde a coleta, transporte e disposição dos afluentes sanitários dentro de uma perspectiva viável e tecnicamente realizável frente aos problemas, recursos disponíveis e a tecnologia atual.
\end{abstract}

PALAVRAS-CHAVE: Esgotamento sanitário. Habitação de interesse social. Infra-estrutura urbana.

PROPOSAL FOR SANITATION IN

SOCIAL INTEREST HOUSING IN TOCANTINS, BRAZIL

\footnotetext{
${ }^{1}$ Mestre em Engenheira Civil, FAU Mackenzie, Professora. eleana.flain@mackenzie.br.

${ }^{2}$ Doutor em Arquitetura e Urbanismo, FAU Mackenzie, Professor Titular. roberto.righi@mackenzie.br.
} 


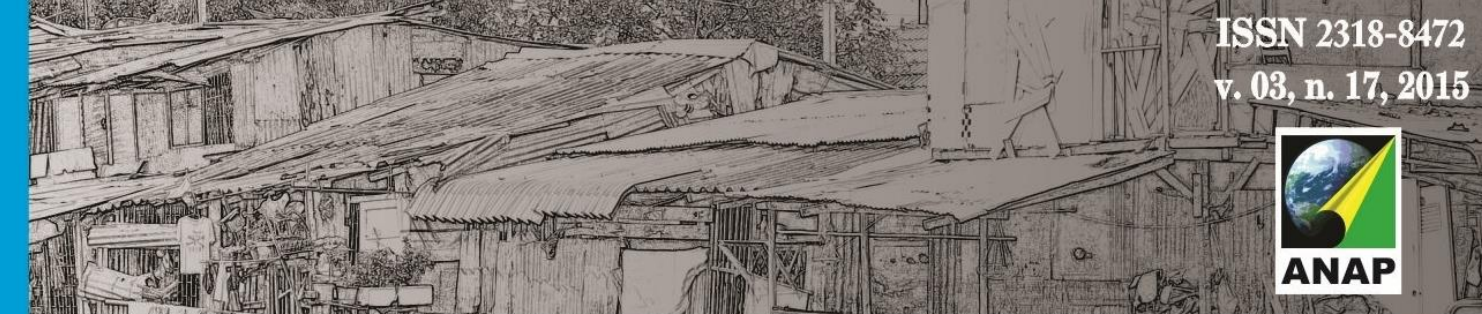

Revista Nacional de

Gerenciamento de Cidades

\section{INTRODUÇÃO}

Segundo Oliveira $(2001, p .1)^{3}$, "...o fenômeno de urbanização agravou o histórico quadro de exclusão social, marginalização e violência". O pensamento deste autor expressa uma condição muito presente no estado do Tocantins foco de intensos processos de migração inter-regionais e rápida urbanização recente, com conseqüente emergência deste grave quadro social.

Segundo a Constituição Federal de 1988, a habitação é um direito social (art. 6‥) de todo o cidadão brasileiro. Programar e promover a habitação ao povo brasileiro e, principalmente, aos menos favorecidos é competência comum da União, Estados, Distrito Federal e Municípios (art. 23, IX) ${ }^{4}$. Na $1^{\text {a. }}$ Conferência das Cidades que ocorreu em Brasília entre 01 e 03 de dezembro de 1999 conclamou a ampla mobilização da população em defesa da Reforma Urbana, do direito à moradia, ao transporte, ao saneamento, à infraestrutura, enfim, do direito à cidade. (Habitar, 2000, p.17-20) . Os princípios apresentados pela Constituição Federal de 1988, junto com as posições da $1^{\text {a }}$ Conferência das Cidades expressam direcionamentos para o exercício das Secretarias de Habitação responsáveis pela execução da política habitacional, do controle do uso e da ocupação do solo e da promoção para preservação da paisagem e do meio ambiente, nos âmbitos dos governos federal estadual e municipais. Dentro desta perspectiva mais ampla apresentada, devido a sua extensão e complexidade, adota-se neste trabalho o recorte do sistema de esgotamento sanitário para habitação de interesse social, analisando, diagnosticando e propondo solução alternativa para municípios do estado do Tocantins.

Numa escala mais ampla, o primeiro levantamento nacional sobre saneamento básico no Brasil foi realizado em 1974, através de convênio celebrado

\footnotetext{
${ }^{3}$ Oliveira, Isabel Cristina Eiras de. Estatuto da cidade: para compreender.... Rio de Janeiro: IBAM/DUMA, 2001.

${ }^{4}$ www.senado.gov.br/legislacao/const/con1988/CON1988_13.07.2010/art_6_.shtm

${ }^{5}$ Habitar. São Paulo : Conam, 2000. n. 2, fev. 2000, p.17-20.
} 


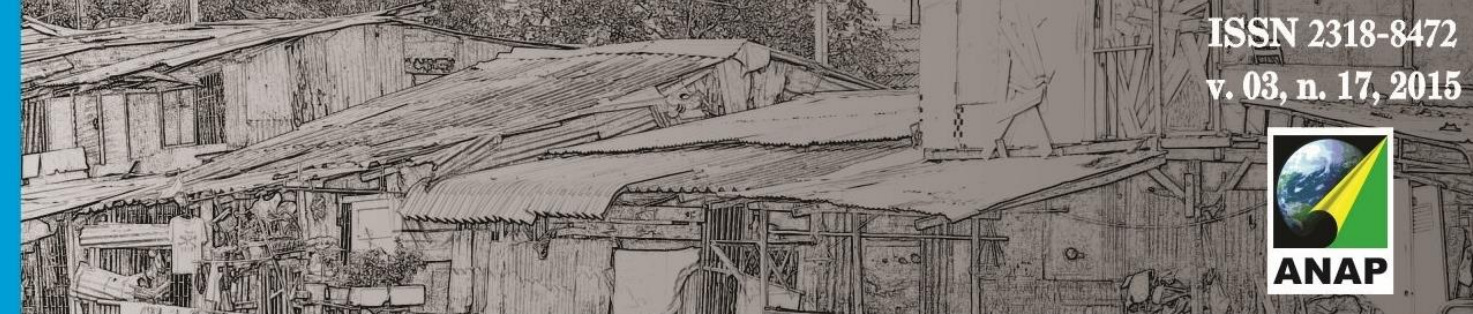

\section{Revista Nacional de}

Gerenciamento de Cidades

emissários e acessórios), as estações elevatória e de tratamento, a vizinhança da estação de tratamento, o corpo receptor e os usos da água, além das comunidades aquáticas e fauna da região. É importante salientar que o sistema de esgotamento sanitário deverá ser totalmente estanque.

É inegável que a implementação de um sistema de esgotamento sanitário em uma determinada região melhora as condições ambientais ao mesmo tempo em que, também, pode mudar a paisagem em torno dos empreendimentos e como conseqüência desses fatos deve alterar a percepção do ambiente pela população. Neste sentido recentemente, diversos autores, entre eles (Bay; Silva, 2011, p. 97$112)^{9}$, tem estudado a percepção ambiental e como a implementação de esgotamento sanitário em determinadas regiões tem mudado a percepção dos ambientes pela população usuária.

\section{JUSTIFICATIVA}

A Lei $11.445^{10}$, de $5 / 1 / 2007$, regulamentada pelo Decreto $n^{\circ} .7 .217$, de 21/6/2010, estabelece diretrizes nacionais para o saneamento básico no País e determina, no seu art. 52, a elaboração do Plano Nacional de Saneamento Básico, sob a coordenação do Ministério das Cidades.

O Governo Federal e o Conselho das Cidades (ConCidades) estão trabalhando na continuidade do processo de elaboração do Plano Nacional de Saneamento Básico (Plansab), sob a coordenação da Secretaria Nacional de Saneamento Ambiental do Ministério das Cidades, conforme determina a Lei 11.445/2007 e a Resolução Recomendada ํㅡㄴ 33, de 1\%/03/2007, do ConCidades.

A elaboração do Plansab tem como função, entre outros, definir diretrizes para o saneamento básico nacional, sendo nele, estabelecido, também, os objetivos

9 Bay A. M. C.; Silva, V. P. Percepção ambiental de moradores do Bairro de Liberdade de Parnamirim/RN sobre esgotamento sanitário. In: HOLOS, 2011, Ano 27, Vol 3, p. 97-112 (Acesso em 19/10/2014)

${ }^{10}$ www.planalto.gov.br/ccivil_03/_ato2007-2010/2007/lei/l11445.htm 


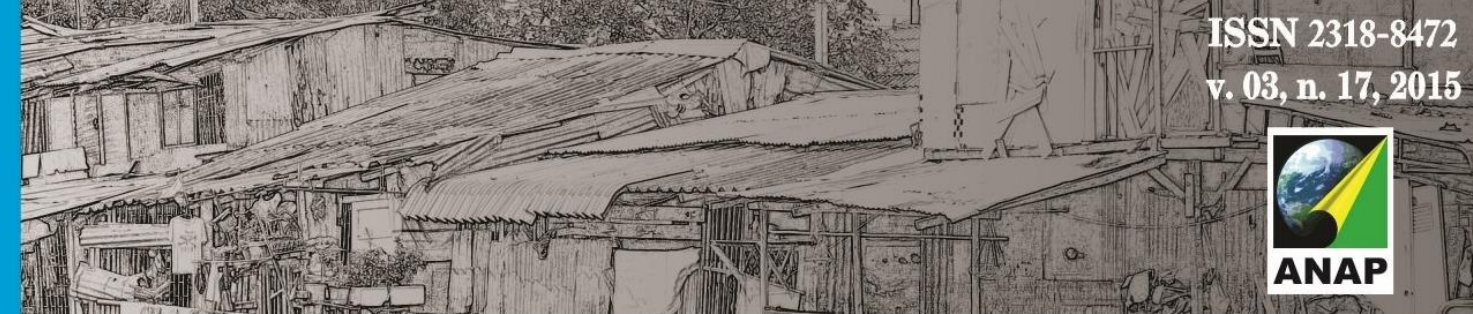

Revista Nacional de

Gerenciamento de Cidades

e as metas nacionais e macrorregionais e estratégias de governo para o setor no horizonte dos próximos vinte anos em busca da universalização e do aperfeiçoamento na gestão dos serviços de saneamento básico em todo o País como um direito social.

O Plansab, quando aprovado em sua etapa final, constitui o eixo central da política federal para o saneamento básico, promovendo a articulação nacional dos entes da federação para a implementação das diretrizes estabelecidas na Lei $11.445 / 07$.

De uma forma mais ampla e atualizada no contexto da Reforma Urbana, amplamente discutida na $1^{\text {a }}$. Conferência das Cidades em 1999 (Habitar, 2000, p.17$20)^{11}$, os serviços de saneamento básico contemplam os componentes de abastecimento de água potável, esgotamento sanitário, limpeza urbana e manejo de resíduos sólidos, e drenagem e manejo das águas pluviais urbanas.

Segundo a Publicação Gasto Público em Saneamento Básico $(2009)^{12}$, em relação aos indicadores de acesso aos serviços de saneamento básico, dados da Pesquisa Nacional por Amostragem Domiciliar, referente ao ano de 2008, divulgados pelo Instituto Nacional de Geografia e Estatística (IBGE), mostram que a rede geral de esgotamento sanitário está disponível para $52,5 \%$ dos domicílios do Brasil. Considerando-se, também, a população que tem acesso ao esgotamento sanitário por fossa séptica esse percentual sobe para $73,17 \%$. Acrescenta ainda que a adoção do sistema fossa séptica e sumidouro diminuiu em todas as regiões do País, exceto na Região Norte , aumentou em 3,2\%.

A grande e crescente escassez de recursos hídricos em quantidade e em qualidade adequada para as diferentes necessidades humanas tem incentivado cada vez mais o desenvolvimento de pesquisas para a busca e aprimoramento de soluções para o tratamento de esgoto sanitário. Observa-se que a ausência de

\footnotetext{
${ }^{11}$ Habitar. São Paulo : Conam, 2000. n. 2, fev. 2000, p.17-20.

12 Gasto Público em Saneamento Básico. Governo Federal e Fundos Financiadores. Relatório de Aplicações de 2009. Ministério das Cidades.
} 


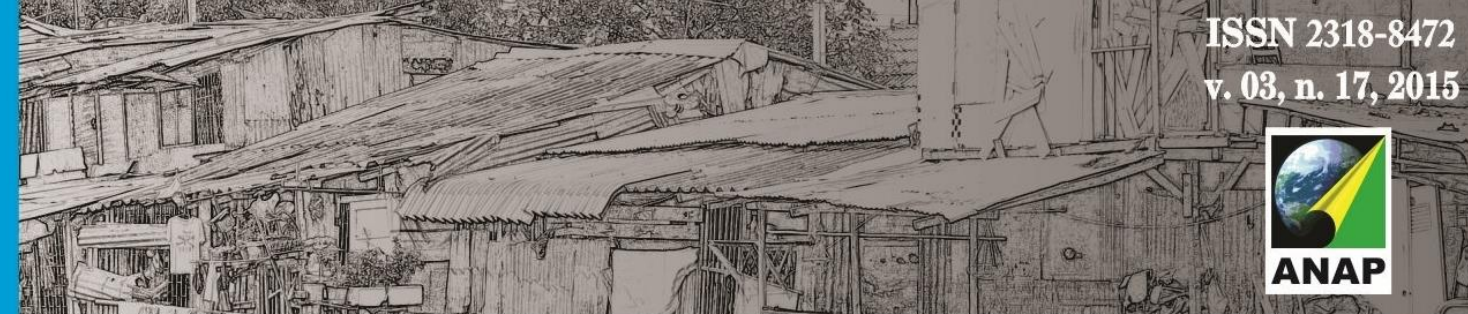

\section{Revista Nacional de}

Gerenciamento de Cidades

tratamento e a disposição inadequada dos esgotos sanitários são umas das principais causas da deterioração dos recursos naturais, em especial dos hídricos necessários para o desenvolvimento humano e das cidades.

\section{METODOLOGIA}

A metodologia para o desenvolvimento da pesquisa e para o sistema de esgotamento proposto baseou-se na análise bibliográfica, em dados obtidos em levantamento de campo e de estudo de caso.

Quando em visita técnica realizada em abril de 2011 a diversos Municípios pertencentes a Microrregião conhecida como Bico do Papagaio no Estado do Tocantins, a saber: Buriti do Tocantins (Quebradeiras de Côco), Carrasco Bonito, São Miguel (no Povoado de Grota do Meio), Sítio Novo (no Povoado de Sumaúma), Praia Norte (no Centro Urbano e Povoado de São Félix) entre outros, observou-se "in loco" fatores relevantes em relação ao esgotamento sanitário de 825 Unidades Habitacionais de Interesse Social onde não há sistema de coleta de esgoto municipal. É importante salientar que todas estas unidades habitacionais foram projetadas e construídas a partir de iniciativas governamentais. Infelizmente, por diversos motivos, tecnicamente e a partir do uso recente mostram sérias deficiências, que podem levar a desastres sanitários, com a contaminação de cursos d'água, lençol freática e da própria população. A proposta técnica a ser apresentada foca na substituição e melhoria do sistema existente, individualizado para um coletivo.

Os principais aspectos identificados visando a compreensão das deficiências e sua superação são a seguir apresentados:

- O sistema fossa séptica e sumidouro foram executados em local onde o lençol freático está quase aflorando;

- O sistema fossa séptica e sumidouro foram executados em margens de córregos e ou rios; 


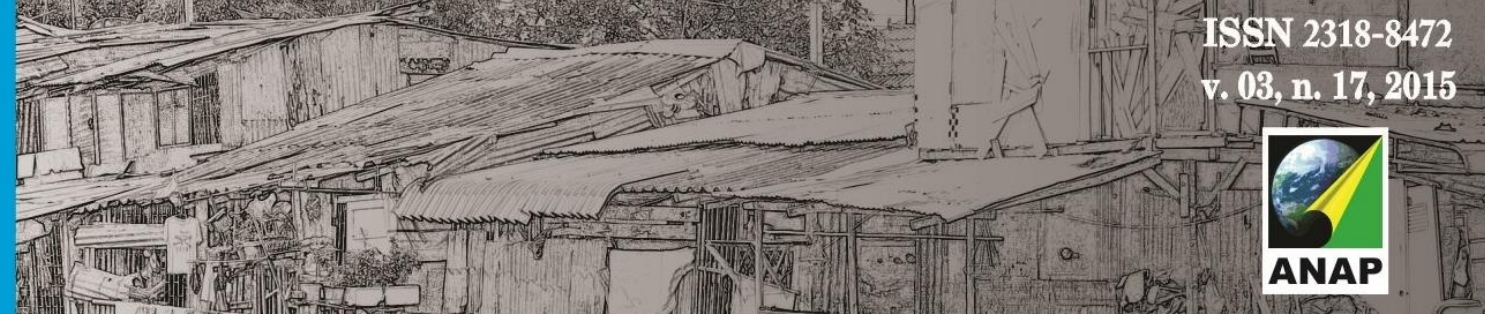

\section{Revista Nacional de}

Gerenciamento de Cidades

- O esgoto sanitário estava aflorando a superfície do terreno;

- O esgoto sanitário conduzido por canalização improvisada para a rua;

- Os moradores, principalmente crianças e animais domésticos, estavam em contato direto com o esgoto sanitário;

- Constatou-se total falta de conhecimento, da população de maneira geral, acerca das consequências do contato, de humanos e animais domésticos, com materiais provenientes do esgotamento sanitário e da contaminação do lençol freático.

Em função do estudo de caso e do que foi constado "in loco" pode ser observado na figura 01 feita quando durante as visitas às unidades habitacionais de interesse social no Estado do Tocantins.

Diante desta realidade impactante apresenta-se a seguir uma proposta técnica alternativa para o sistema de esgotamento sanitário considerando-se principalmente os seguintes aspectos essenciais: baixo custo, facilidade de instalação e de manutenção.

Como estudo de caso, adota-se a Microrregião Bico do Papagaio, por ser de maior relevância para a Região Norte do Estado do Tocantins.

Figura 01: Fossa séptica transbordando no quintal da unidade habitacional (Carrasco Bonito)

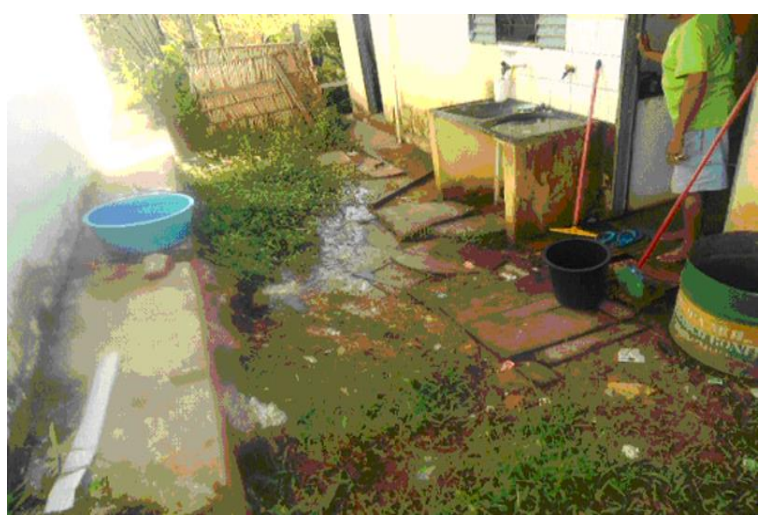

Fonte: ARQUIVO PESSOAL DA AUTORA, 2011. 


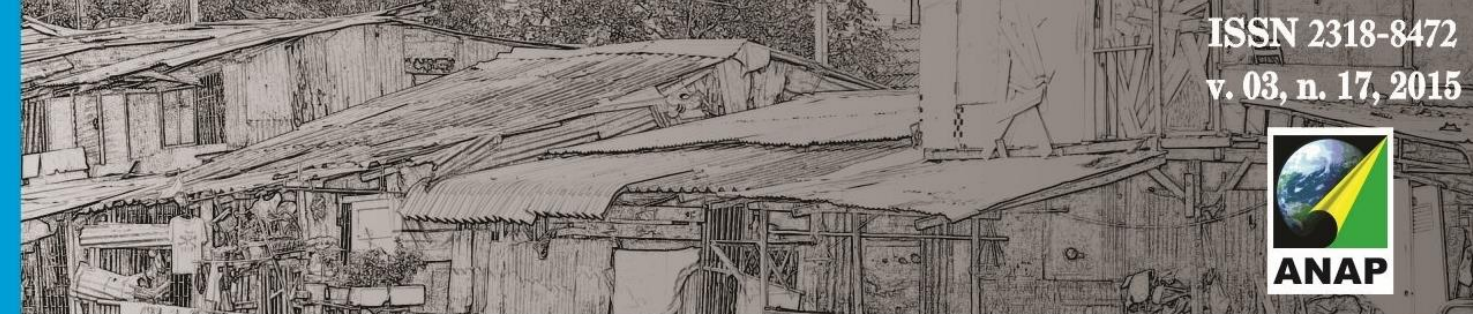

\section{Revista Nacional de}

Gerenciamento de Cidades

A microrregião localizada no norte do estado do Tocantins conhecida como Bico do Papagaio é pertencente à mesorregião Ocidental do Tocantins. A população estimada nessa região, em 2006 pelo IBGE, foi de 198.388 habitantes que está dividida em 25 municípios dos 139 do Tocantins. Possui uma área total de $15.767,856 \mathrm{~km}^{2}$. Dentre os 25 municípios estão incluindo aqueles que foram visitados, objeto deste trabalho. A microrregião limita-se ao norte com os estados do Pará à esquerda e do Maranhão à direita.

Os últimos resultados do censo (IBGE, 2010) ${ }^{13}$ mostram que o Brasil possui 16,2 milhões de brasileiros que vivem em extrema pobreza, o equivalente a $8,5 \%$ da população. No Tocantins, esse percentual chega a $11,8 \%$ da sua população vivendo em extrema pobreza, são cerca de 163 mil do total de 1.383 .445 habitantes. O IDHM (Índice de Desenvolvimento Humano do Município) de Palmas é de 0,699, enquanto que a cidade de São Paulo o IDHM é 0,805 com uma população estimada em 11.895.893. Este índice, segundo o PNUD ${ }^{14}$, é uma medida composta de indicadores de três dimensões do desenvolvimento humano: longevidade, educação e renda, que varia de 0 a 1 . Quanto mais próximo de 1, maior o desenvolvimento humano.

$\mathrm{Na}$ tabela 01 é apresentada uma síntese das informações referentes ao último censo, segundo IBGE (2010), de cada um dos municípios visitados. Observase que todos eles apresentam um IDHM entre 0,5 e 0,6, abaixo do IDHM da capital Palmas, o que demonstra o nível de extrema pobreza dos municípios visitados.

\footnotetext{
${ }^{13}$ www.cidades.ibge.gov.br/xtras/perfil.php?lang=\&codmun=170255\&search=tocantins|augustinopolis $\mid \mathrm{i}$ nfograficos informacoes-completas (Acesso em 20/10/2014)

${ }_{14}$ Programa das Nações Unidas para o Desenvolvimento (www.pnud.org.br/idh/IDHM.aspx?indiceAccordion=0\&li=li_IDHM) / Acesso em 20/02/2015.
} 


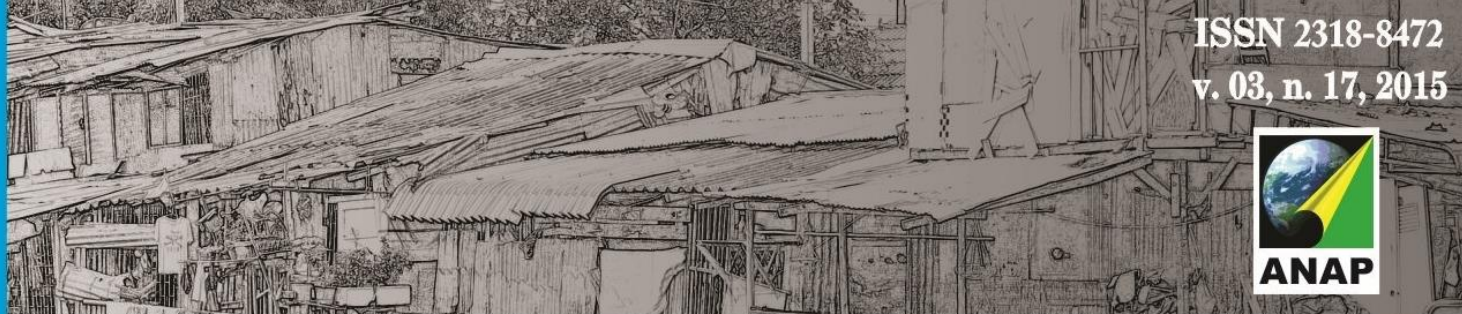

Revista Nacional de

Gerenciamento de Cidades

\section{REFERÊNCIA BIBLIOGRÁFICA}

Associação Brasileira de Cimento Portland - ABCP. Manual Técnico para Implementação - Habitação 1.0 - Bairro Saudável. População Saudável. São Paulo, Associação Brasileira de Cimento Portland, Setembro/2002. p. 69; 88 p. In: www.abcp.org.br/conteudo/wpntent/uploads/2010/01/Manual_Habitacao_10.pdf (Acesso em 18/10/2014)

Associação Brasileira de Normas Técnicas - NBR 7229/93. Projeto, construção e operação de sistemas de tanques sépticos. Rio de Janeiro, 1993.

NBR - 13969/97 Tanques sépticos - Unidades de tratamento complementar e disposição final dos efluentes líquidos - Projeto, construção e operação. Rio de Janeiro, 1997.

Bay A. M. C.; Silva, V. P. Percepção ambiental de moradores do Bairro de Liberdade de Parnamirim/RN sobre esgotamento sanitário. In: HOLOS, 2011, Ano 27, Vol 3, p. 97-112 (Acesso em 19/10/2014)

Gasto Público em Saneamento Básico. Governo Federal e Fundos Financiadores. Relatório de Aplicações de 2009. Ministério das Cidades.

Elementos conceituais para o saneamento básico./ HELLER, L. (Coord.); Léo Heller; Uende Aparecida Figueiredo Gomes. Brasília: Ministério das Cidades/Secretaria Nacional de Saneamento Ambiental, 2011. (In: Panorama do Saneamento Básico no Brasil, v. 1)

Habitar. São Paulo : Conam, 2000. n. 2, fev. 2000, p.17-20.

Instituto Brasileiro de Geografia e Estatística (IBGE). In: www.ibge.gov.br (Acesso em 19/10/2014)

Lei 11.445, de 5/1/2007 (presrepublica.jusbrasil.com.br/legislacao/95020/lei-de-saneamento-basicolei-11445-07; Acesso em 20/10/2014)

Oliveira, Isabel Cristina Eiras de. Estatuto da cidade: para compreender.... Rio de Janeiro: IBAM/DUMA, 2001.

Panorama do Saneamento Básico no Brasil: cadernos temáticos para o panorama do saneamento básico no Brasil. HELLER, L. (Coord.); REZENDE, S. (Org.). Brasília: Ministério das Cidades/Secretaria Nacional de Saneamento Ambiental, 2011. (In: Panorama do Saneamento Básico no Brasil, v. 7)

PAIM, J. S.; TEIXEIRA, C. F.. Política, planejamento e gestão em saúde: balanço do estado da arte. Rev Saúde Pública 2006, 40 (NEsp): 73-8 (In: www.scielo.br/pdf/rsp/v40nspe/30625.pdf )

Pesquisa Nacional de Saneamento Básico 2008. Rio de Janeiro: Ministério do Planejamento, Orçamento e Gestão / Instituto Brasileiro de Geografia e Estatística - IBGE, 2010.

Programa exibido em 31/05/2012, no Jornal Nacional, da Rede Globo. 


\section{Revista Nacional de}

Gerenciamento de Cidades

\section{Webgrafia}

www.cidades.gov.br/plansab (Acesso em 01/09/2014)

www.senado.gov.br/legislacao/const/con1988/CON1988_13.07.2010/art_6_.shtm 20/10/2014)

www.finep.gov.br/prosab/esgoto.htm\#atuacao (Acesso em 24/10/2014)

www.fjp.mg.gov.br/index.php/estatisticas-e-indicadores (Acesso em 20/10/2014) 